\title{
Potent anticancer activity of cystine-based dipeptides and their interaction with serum albumins
}

\author{
Biswadip Banerji ${ }^{1 *}$, Sumit Kumar Pramanik ${ }^{1}$, Uttam Pal$^{2}$ and Nakul Chandra Maiti ${ }^{2}$
}

\begin{abstract}
Background: Cancer is a severe threat to the human society. In the scientific community worldwide cancer remains a big challenge as there are no remedies as of now. Cancer is quite complicated as it involves multiple signalling pathways and it may be caused by genetic disorders. Various natural products and synthetic molecules have been designed to prevent cell proliferation. Peptide-based anticancer drugs, however, are not explored properly. Though peptides have their inherent proteolytic instability, they could act as anticancer agents.
\end{abstract}

Results: In this present communication a suitably protected cystine based dipeptide and its deprotected form have been synthesized. Potent anticancer activities were confirmed by MTT assay (a laboratory test and a standard colorimetric assay, which measures changes in colour, for measuring cellular proliferation and phase contrast images. The $\mathrm{IC}_{50}$ value, a measure of the effectiveness of a compound in inhibiting biological or biochemical function, of these compounds ranges in the sub-micromolar level. The binding interactions with serum albumins (HSA and BSA) were performed with all these molecules and all of them show very strong binding at sub-micromolar concentration.

Conclusions: This study suggested that the cystine-based dipeptides were potential anticancer agents. These peptides also showed very good binding with major carrier proteins of blood, the serum albumins. We are currently working on determining the detailed mechanism of anticancer activity of these molecules.

Keywords: Peptide, Anticancer, Serum albumin, Spectroscopy, Docking

\section{Introduction}

Cancer has been an ever-growing public problem since its appearance and the estimated worldwide new incidence of it is about 6 million cases per year [1-4]. It is the second major cause of death after cardiovascular disease [5]. This disease is now well characterized by unregulated proliferation of cells [6,7]. There has long been a search for a therapeutic agent to inhibit or control cell proliferation. Various natural products along with synthetic molecules are continuously explored to achieve development of a viable anticancer molecule [8-10]. Peptides are very versatile biological molecules. Except for a few inherent problems, peptides or peptide-based

\footnotetext{
* Correspondence: biswadip.banerji@gmail.com

${ }^{1}$ Department of Chemistry, CSIR-Indian Institute of Chemical Biology, 4, Raja S.C. Mullick Road, Kolkata 700032, India

Full list of author information is available at the end of the article
}

molecules are most bio-compatible [11,12]. Compared with traditional treatments such as chemotherapy, peptides with high specificity against cancer cells may present an alternate way of killing cancer cells while protecting normal cells [13]. Many natural or synthetic peptides have been reported to show anticancer activity [14]. Peptide-based (or peptide-derived) anticancer drugs have the potential to selectively target and disrupt the signalling pathways in the course of carcinogenesis [15]. In the present study, we have synthesized a few cystine based dipeptide compounds (protected and deprotected L-Cys-L-Cys, L-Cys-D-Cys, 1A-1D) (Figure 1). These compounds show anticancer activity against different cancer cell lines. In addition, we performed an interaction study of them with serum albumins. In blood all the drugs must bind with the serum albumins in order to reach the target site [16-18]. Therefore, the study of serum protein
(C) Chemistry Central

(C) 2013 Banerji et al.; licensee Chemistry Central Ltd. This is an Open Access article distributed under the terms of the Creative Commons Attribution License (http://creativecommons.org/licenses/by/2.0), which permits unrestricted use, distribution, and reproduction in any medium, provided the original work is properly cited. 


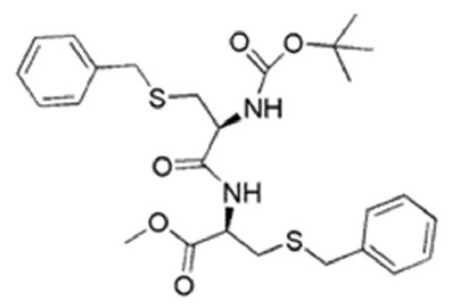

A

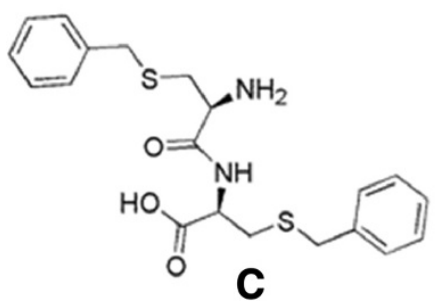

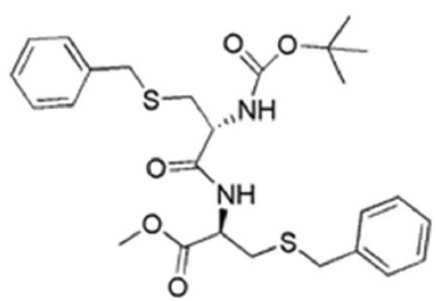

B

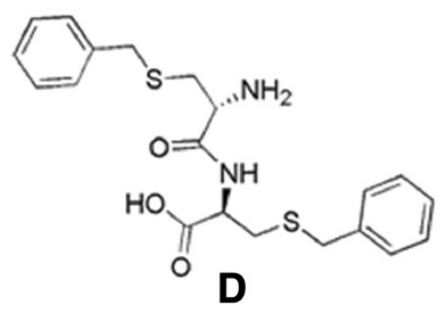

Figure 1 The structures of cysteine derived dipeptide compounds. Where $\mathbf{A}$ corresponds to $1 \mathbf{A}$, B corresponds to $1 \mathbf{B}$, C corresponds to 1 C and $\mathbf{D}$ corresponds to $1 \mathbf{D}$ respectively.

binding with a newly synthesized drug molecule is very important [19-21]. In this paper we wish to disclose the sub-micromolar anticancer activity of these peptides and their binding interactions with serum albumins (BSA and HSA). Cell viability assay was done by MTT-assay while the binding studies were carried out using fluorescence spectroscopy, circular diachroism, molecular modelling and computational analysis. The lowmicromolar anticancer activity may be further improved by changing different protection groups.

\section{Experimental methods}

\section{Cell culture}

Neura 2a (neuroblastoma cell line), Hek 293 (kidney cancer cell line) and Hep G2 (liver cancer cell line) were procured from the National Centre for Cell Sciences (NCCS, Pune, India) and were grown in Dulbecco's modified Eagle medium antibiotics (penicillin/streptomycin and gentamicin). Cells were cultured at $37^{\circ} \mathrm{C}$ in $95 \%$ air and $5 \% \mathrm{CO}_{2}$ humidified incubators. Hep G2 cells were seeded at a density of $10^{5}$ well plated in 96 well plates. Cells were typically grown to $60-70 \%$ confluence, rinsed in phosphate-buffered saline (PBS) and placed into serum-free medium overnight prior to treatments. After overnight incubation, the Hep G2, HEK 293, and Neura 2a cells were treated with these compounds separately at the concentration of $1 \mu \mathrm{M}, 10 \mu \mathrm{M}$ and $20 \mu \mathrm{M}$, respectively. After 48 hours the medium was removed and a $50 \mu \mathrm{l}$ of fresh medium was added along with $10 \mu \mathrm{l}$ of MTT (3-(4,5-Dimethylthiazol-2-yl)-2,5-diphenyltetrazolium bromide). MTT solution $(5 \mathrm{mg} / \mathrm{ml})$ was slowly removed after 4 hours and the purple crystals with solubilization in $1.4 \mathrm{ml}$ of DMSO. The absorbance was measured at test wavelength of $550 \mathrm{~nm}$ in Elisa Plate Reader [22,23].

\section{Fluorescence}

The steady-state fluorescence spectra were recorded with a Perkin Elmer LS-45 spectrofluorophotometer. Emission spectra were recorded with an excitation wavelength of $280 \mathrm{~nm}$ and emission range of 290-450 nm. Both the excitation and emission slit widths kept at $5 \mathrm{~nm}$ each. The intrinsic fluorescence of tryptophan residue(s) in the protein was measured in the presence and in the absence of the dipeptides. Most of the experiment was carried out at room temperature $\left(25^{\circ} \mathrm{C}\right)$, Some temperature dependent studies were carried out using water bath.

The fluorescence of the protein was found to quench in the presence of the peptides. The quenching experiment was carried out simply by adding small aliquote $(1-10 \mu \mathrm{L}$ from $100 \mu \mathrm{M}$ stock solution) of concentrated peptide solution to $1 \mathrm{~mL}$ solution containing an appropriate concentration of HSA/BSA $(0.5 \mu \mathrm{M}$ in $20 \mathrm{mM}$ Tris- $\mathrm{HCl}$ buffer, $\mathrm{pH}$ 7.5) taken in $1 \mathrm{~cm}$ path length quartz cuvette. The optical density of the solution at the excitation wavelength was kept less than 0.05 . Small error due to dilution upon addition of the peptide was neglected. The peptides showed negligible absorbance at the excitation wavelength $(280 \mathrm{~nm})$. Fluorescence intensities at $340 \mathrm{~nm}$ were recorded as a function of ligand concentration. To derive the binding parameters, obtained data were analyzed using modified Stern-Volmer equation [24-26].

\section{Measurements of circular dichroism (CD)}

The Far-UV CD spectra have been measured on a Jasco J-810 spectrometer using a $1.0 \mathrm{~mm}$ quartz cell under constant nitrogen flow condition and at room temperature. The CD spectra of HSA and BSA have been recorded in the absence and presence of these compounds within the wavelength range of 200-250 
$\mathrm{nm}$. The CD results have been represented in terms of ellipticity $(\theta)$.

\section{Docking}

The crystal structure of HSA and BSA were obtained from Protein Data Bank (PDB ID: 1E78 and 3V03 respectively). Structures of the synthesized compounds were drawn in Gauss View followed by geometry optimization in Gaussian 09 with DFT level of theory using B3LYP/6-31 + G(d,p) basis set. AutoDock 4 and MGLTools of The Scripps Research Institute were used to perform the docking calculations [27,28]. Docking was performed following the previously published protocol [29-33]. The PyMOL molecular (http://pymol.org/) viewer and the MGLTools were used to render the output.

\section{Results and discussion Cell viability}

In order to determine the biological efficacy of these newly synthesized compounds in vitro cell culture system has been used.

Cell viability was quantified by MTT, a yellow tetrazole assay, where the viable cells were determined by the reduction of the yellow MTT into purple formazan product. For this assay, the cells were plated in 96 well plates and grown in monolayer and then treated with these compounds of interest. The viability of cells by MTT assay was performed 48 hours post treatment as described before. Finally, the medium was removed and replenished with $80 \mu \mathrm{l}$ of fresh medium along with $20 \mu \mathrm{l}$ of MTT $(5 \mathrm{mg} / \mathrm{ml})$. After 4 hours, MTT solution was slowly removed and the purple crystals were solubilised in $100 \mu \mathrm{l}$ of DMSO. The absorbance was measured by a plate reader at a wavelength of $550 \mathrm{~nm}$. The absorbance obtained from treated cells were expressed as percentages of absorbance obtained from untreated cells and are reported as mean $\pm \operatorname{SEM}(n=3)$.
For screening the activity, the cultured cells were exposed to these compounds at three different concentrations $(1.0 \mu \mathrm{M}, 10 \mu \mathrm{M}$ and $20 \mu \mathrm{M})$ and incubated for 48 hours. Viability was assessed by MTT assay as described. All the four compounds showed significant reduction in the amount of viable cells in all the three cell lines screened. The results are shown graphically below, Figure 2a-c, respectively. From the bargraph it is observed that these peptides cause significant reduction of viable cells in this screening assay.

The compounds $1 \mathrm{~A}$ and $1 \mathrm{~B}$ show more cytotoxicity than compounds $1 \mathrm{C}$ and $1 \mathrm{D}$ at a particular concentration. Cytotoxiciy of $1 \mathrm{~A}$ is comparable to $1 \mathrm{~B}$ and the cytotoxicity of $1 \mathrm{C}$ is comparable to $1 \mathrm{D}$. Furthermore, cells were also examined under an inverted phase contrast microscope. For example, Hek 293 cells were treated with these compounds (at $20.0 \mu \mathrm{M}$ concentration) for 24 hours and phase contrast micrographs were taken. As shown in Figure 3, there was massive cell death in response to these two compounds ( $1 \mathrm{~A}$ and $1 \mathrm{C}$ ) as compared to control.

Action of a drug molecule to a cell is initiated by drug receptor and many of the receptors have high specificity for a drug molecule and the chemical structure of a drug may significantly alter the cell's response to the drug molecule. Also the concentration of drug molecule to the receptor site directly affects the drug response. For example, amphetamine and methamphetamine act as powerful stimulus for nervous system and act via the same receptor. These two compounds differed slightly in their chemical structure; however, methamphetamine exerts more powerful action. There are small structural changes present in our synthesized dipeptides. $\mathrm{NH}_{2}$ groups in $1 \mathrm{~A}$ and $1 \mathrm{~B}$ are protected with carbamates, also the carboxylic acid moiety is as a methyl ester. The receptor that initiates the drug action of the dipeptides may show difference in action due to these structural changes. However, similar to many chemical reactions,

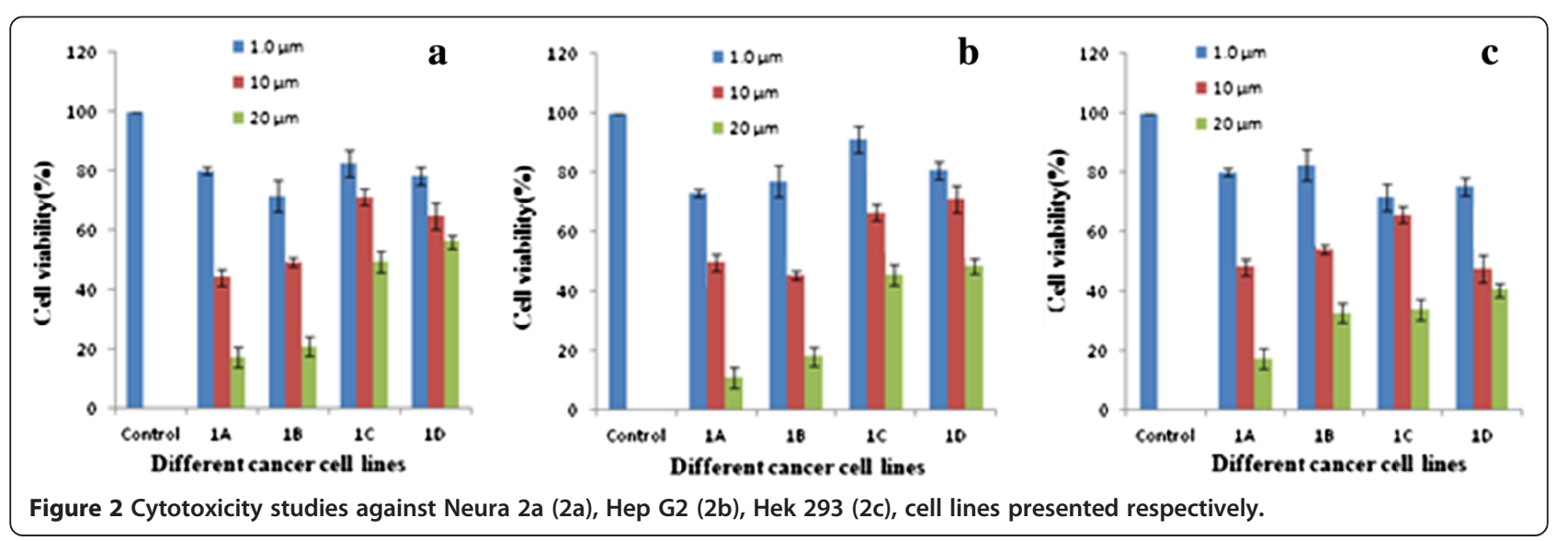




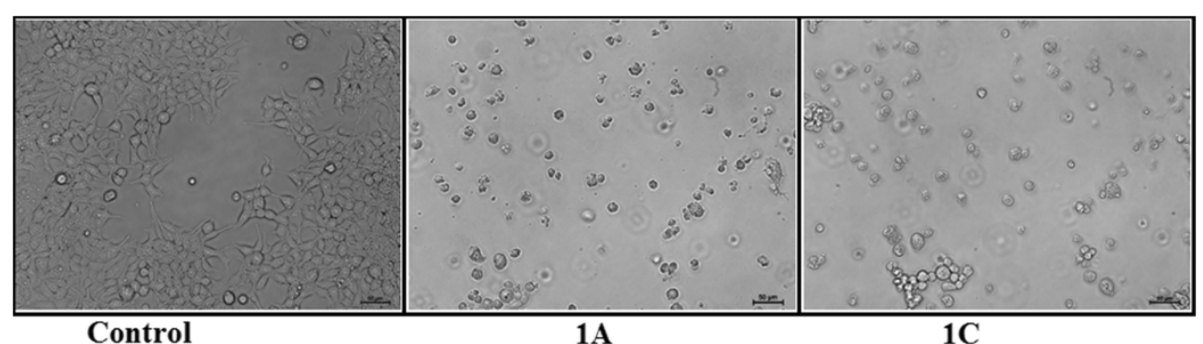

Figure 3 Phase contrast images showing cell death with compounds $1 \mathrm{~A}$ and $1 \mathrm{C}$ at $20.0 \mu \mathrm{M}$ concentration.

drug action of the receptor also depends on the effective concentration of the drug molecule at the receptor site. Amount of drug that penetrates to the cell/receptor site again depends on structure of the drug molecule and their physical parameter such as hydrophobicity. One possible explanation is that $1 \mathrm{~A}$ and $1 \mathrm{~B}$ (cLogP: 4.01, see Additional file 1: Computation of partition coefficient (cLogP)) are more hydrophobic than 1C and 1D (cLogP: 1.75). So, the membrane permeability of these two are more than the other two. So, $1 \mathrm{~A}$ and $1 \mathrm{~B}$ can penetrate the cells better than that of $1 C$ and $1 D$ and could be sensed by the receptor more strongly apart from the structural specificity.

Cell viability tests were performed using cultured cells. However, in real systems, like cells in human body/other animals drugs need to be reached to the body/effected cells by blood. All the drug molecules that enter into the body via systemic circulation get exposed to the blood milieu. In blood, serum protein albumins (HSA, BSA) are the major carrier proteins. They bind to a wide
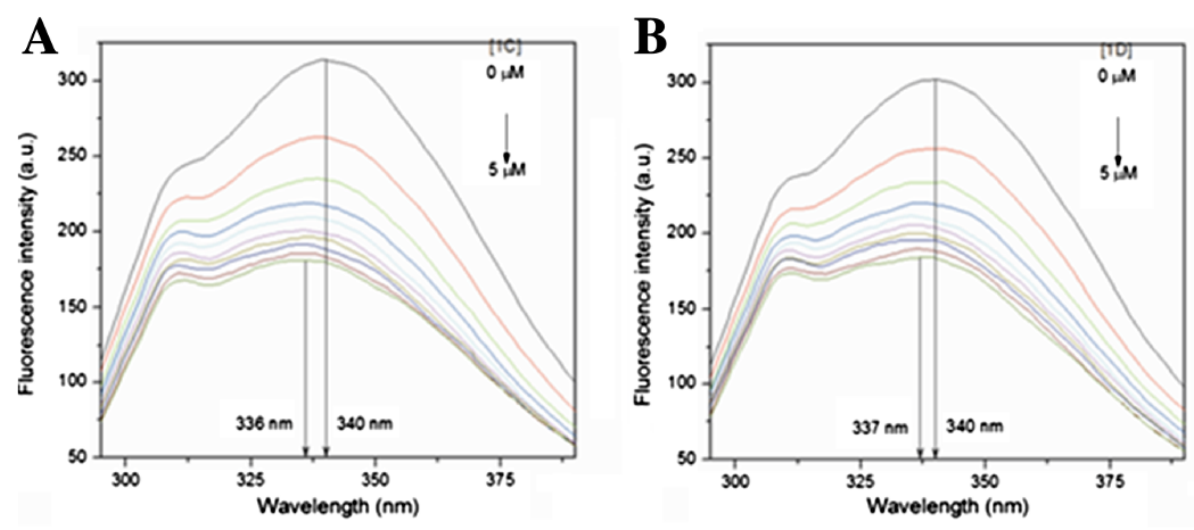

C

D
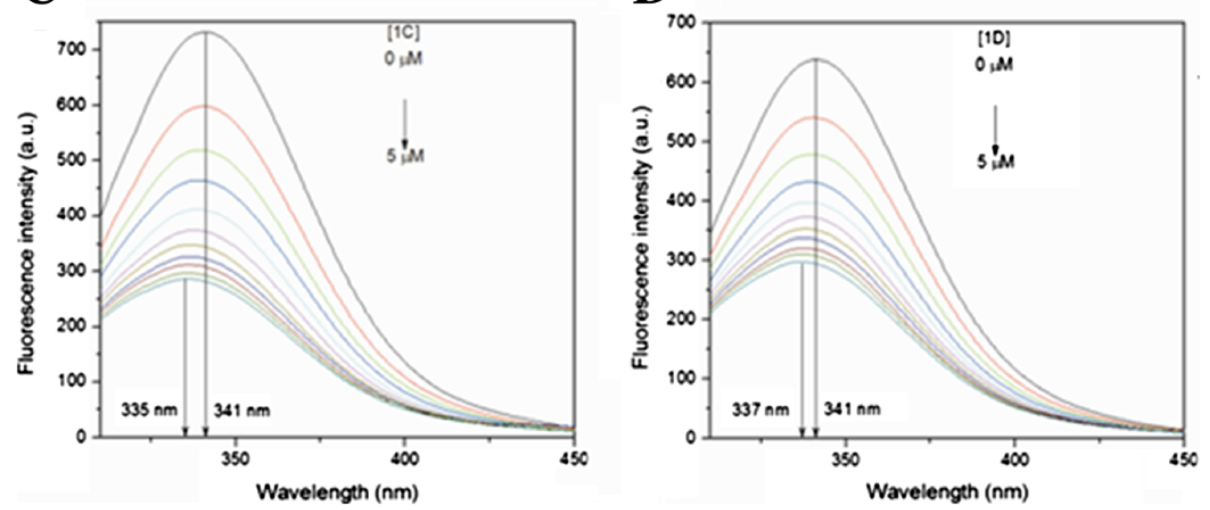

Figure 4 Effect of the compounds on the intrinsic fluorescence of serum albumins. Here $\mathbf{A}$ and $\mathbf{B}$ are Emission spectra of HSA as a function of compound $1 \mathbf{C}$ and $1 \mathbf{D}$ respectively with concentration varying from $0 \mu \mathrm{M}$ to $5 \mu \mathrm{M}$ (10 steps). Figure $\mathbf{C}$ and $\mathbf{D}$ are Emission spectra of BSA as a function of compound $1 \mathbf{C}$ and $1 \mathbf{D}$ respectively with concentration varying from $0 \mu \mathrm{M}$ to $5 \mu \mathrm{M}$ (10 steps). About 4 to $6 \mathrm{~nm}$ blue shift in emission maximum was observed. Excitation maximum, $280 \mathrm{~nm}$; excitation and emission slit $5 \mathrm{~nm}$ each. 
variety of small molecules and fatty acids and carry of them to different parts of the body. Very good binding to these proteins means very good distribution of the drug all over the body i.e., increased bioavailability. Therefore, the binding behaviour of the synthesized peptides to HSA and BSA was carried out using the unique and intrinsic fluorescence from the tryptophan residues. The dipeptides showed very good binding with plasma carrier proteins of both bovine and human. Interaction site of the peptides to the protein was established via molecular docking analysis as discussed later.

\section{Binding constant from fluorescence study}

The fluorescence spectra of HSA / BSA were measured in the presence and absence of cystine based dipeptide compounds. HSA shows a strong fluorescence with a emission peak at $\sim 340 \mathrm{~nm}$ due to its single tryptophan residue (Figure 4). BSA with two tryptophan residues showed similar fluorescence behavior, however, with higher intensity due to the presence of two tryptophan residues in BSA. Cystine based dipeptides (1A, 1B, 1C and 1D) showed no intrinsic fluorescence in solution. However, their (compounds 1A, 1B, 1C and 1D) individual presence in the solution effectively reduced fluorescence yield of HSA / BSA (slight blue shift, $\sim 4 \mathrm{~nm}$ of the fluorescence emission, was within the band width of the measurement). The fluorescence intensity at $340 \mathrm{~nm}$ decreased gradually with increasing peptide concentration, indicating effective fluorescence quenching of the protein fluorescence. Figure 4 shows the spectra in the presence of different concentrations of these dipeptide compounds $1 \mathrm{C}$ and $1 \mathrm{D}$ with HSA and BSA respectively. The quenching spectra for $1 \mathrm{~A}$ and $1 \mathrm{~B}$ with HSA and BSA are shown in Additional file 1: Figure S1.

Fluorescence data in the above experiments can be analyzed using a modified Stern-Volmer (S-V) equation [24] (equation 1). Fluorescence peak intensity values of the protein at different concentration of the compounds were used to fit a modified $\mathrm{S}-\mathrm{V}$ equation as given below:

$$
\frac{F_{0}}{\Delta F}=\frac{1}{f K\lfloor Q\rfloor}+\frac{1}{f}
$$

Where $F_{0}$ is the fluorescence intensity in the absence of an external quencher, $\Delta F$ is the difference in fluorescence in the absence and presence of the quencher at concentration $[Q], K$ is the Stern-Volmer quenching
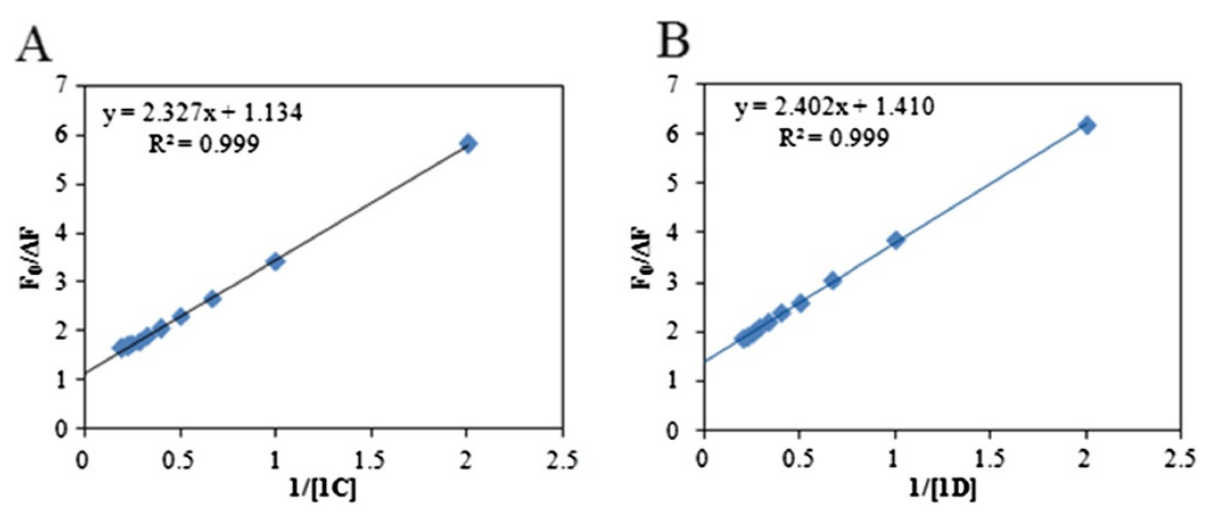

C

D
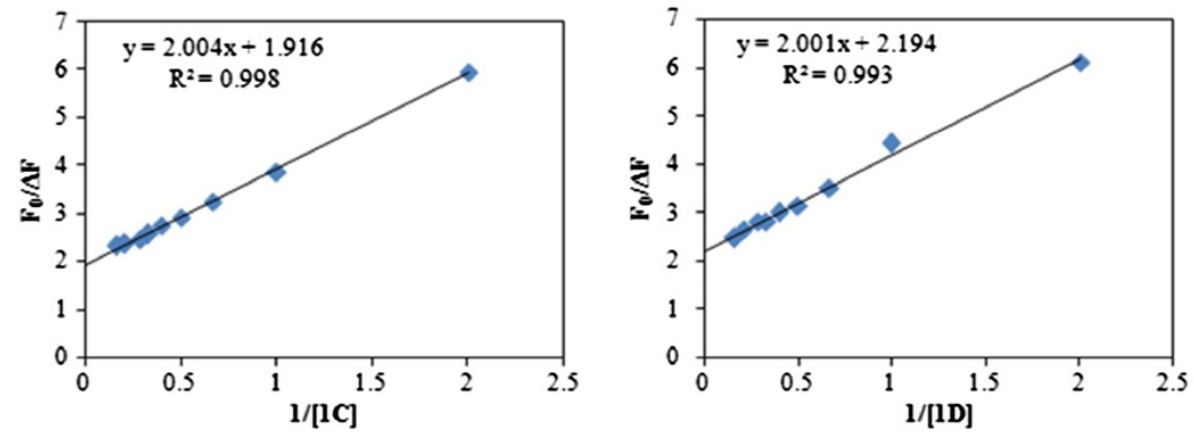

Figure 5 Modified Stern-Volmer plot. (A) and (B) for BSA with compounds 1 C and 1D, respectively. (C) and (D) for HSA with compound 1C and $1 \mathbf{D}$, respectively. 
Table 1 Stern-Volmer quenching constant (K) with HSA and BSA at temperature $298 \mathrm{~K}$ as obtained from equation 1

\begin{tabular}{ccc}
\hline Compounds & \multicolumn{2}{c}{ Stern-Volmer quenching constant $\left(\mathbf{M}^{-\mathbf{1}}\right)$} \\
\cline { 2 - 3 } & HSA & BSA \\
\hline 1A & $18.37 \times 10^{5}$ & $7.95 \times 10^{5}$ \\
\hline 1B & $4.32 \times 10^{5}$ & $3.52 \times 10^{5}$ \\
\hline 1C & $9.56 \times 10^{5}$ & $4.88 \times 10^{5}$ \\
\hline 1D & $10.97 \times 10^{5}$ & $5.90 \times 10^{5}$ \\
\hline
\end{tabular}

constant, and $f$ is the fraction of the initial fluorescence which is accessible to the quencher. The plots of $F_{0} / \Delta F$ versus $1 /[Q]$ (Figure 5) yields $\mathrm{f}^{-1}$ as the intercept, and (f K) ${ }^{-1}$ as the slope. Table 1 shows the result. The intercept on y axis $\left(\mathrm{f}^{-1}\right)$ indicated that $\sim 70-90 \%$ of the total HSA fluorescence and $~ 50 \%$ of BSA fluorescence was accessible for the quenchers (dipeptides). It also suggests that only one tryptophan of BSA was accessible to the quencher. Further temperature dependent experiment showed that quenching constant for all the dipeptides decreased with increasing of temperature (Additional file 1: Table S1). This fact implied that the fluorescence quenching of the protein solution by the peptides was dominated by static quenching mechanism [24-26]. High accessibility of the quencher and the decrease of quenching constant indicated static fluorescence quenching and this static quenching arose from the formation of a dark complex between protein and dipetides [24,25]. The S-V quenching constant as obtained from the modified S-V equation can be shown to be the binding affinity constant, $K_{\mathrm{a}}$ (Additional file 1: Fluorescence Study) [24]. Reciprocal of this $K_{a}$ gives the dissociation constant, $K_{d}$ (Table 2). Contribution of dynamic quenching due to diffusion and collision of the peptides might be negligible as we observed that accesiblity of the peptides to the fluorphore (tryptophan residue in the protein) was high (70-90\% for HSA and 50\% as explained earlier). We observed negligible amount of fluorescence quenching of free tyrptophan in the presence of the dipeptide solution (Additional file 1: Figure S3). This observation added additional support that the quenching of the protein

Table 2 Binding dissociation constants $\left(K_{d}\right)$ with HSA and BSA at temperature $298 \mathrm{~K}$

\begin{tabular}{ccc}
\hline $\begin{array}{c}\text { (SEM }=\text { standard error of } \\
\text { mean; NA = not available) } \\
\text { Compounds }\end{array}$ & \multicolumn{2}{c}{ Binding constant $\left(\mathrm{K}_{\mathrm{d}}\right) \pm$ SEM in $\mu \mathrm{M}$} \\
\cline { 2 - 3 } & HSA & BSA \\
\hline 1A & $0.546 \pm 0.05$ & $1.257 \pm \mathrm{NA}$ \\
\hline 1B & $2.312 \pm \mathrm{NA}$ & $2.840 \pm \mathrm{NA}$ \\
\hline 1C & $1.044 \pm 0.08$ & $2.051 \pm \mathrm{NA}$ \\
\hline 1D & $0.912 \pm \mathrm{NA}$ & $1.703 \pm 0.07$ \\
\hline
\end{tabular}

fluorescence by dipeptides was largely due to association of the dipeptides close to the tryptophan residue in the protein. It supported the view that the peptides may be incorporated close to the tryptophan residue in the proteins and formed a close association (dark complex) and quenched fluorescence [26].

There is the same relationship between $1 \mathrm{~A}$ and $1 \mathrm{~B}$ that between $1 \mathrm{C}$ and 1D: diastereoisomers. However, all the four compounds showed similar binding efficiency (Tables 1 and 2). It indicated that both the conformations are equally significant in the attenuation of HSA/BSA fluorecence. Eftink et. al. and others clearly indicated how the quenching volume and the entry of the quencher to the hydrophobic protein pocket influence both the static and dynamic quenching [24-26]. As in this investigation no significant difference occurred in quenching efficiency (quenching / binding constant), the dipeptides had similar accessibility of the tryptophan residues in the proteins.

\section{Circular dichroism (CD)}

The effect of binding of these compounds on the secondary structure of the protein has been determined through far-UV circular dichroism (CD). The CD spectra for HSA (Figure 6) observed in the range 200-250 $\mathrm{nm}$ reveal the presence of two bands at $\sim 209 \mathrm{~nm}$ and $\sim 222 \mathrm{~nm}$, typically characteristic of $\alpha$-helicity as consistent with the literature. Binding of the compounds $(1 \mathrm{~A}, 1 \mathrm{~B}, 1 \mathrm{C}$ and $1 \mathrm{D})$ to the proteins resulted in slight change in the secondary structure of the

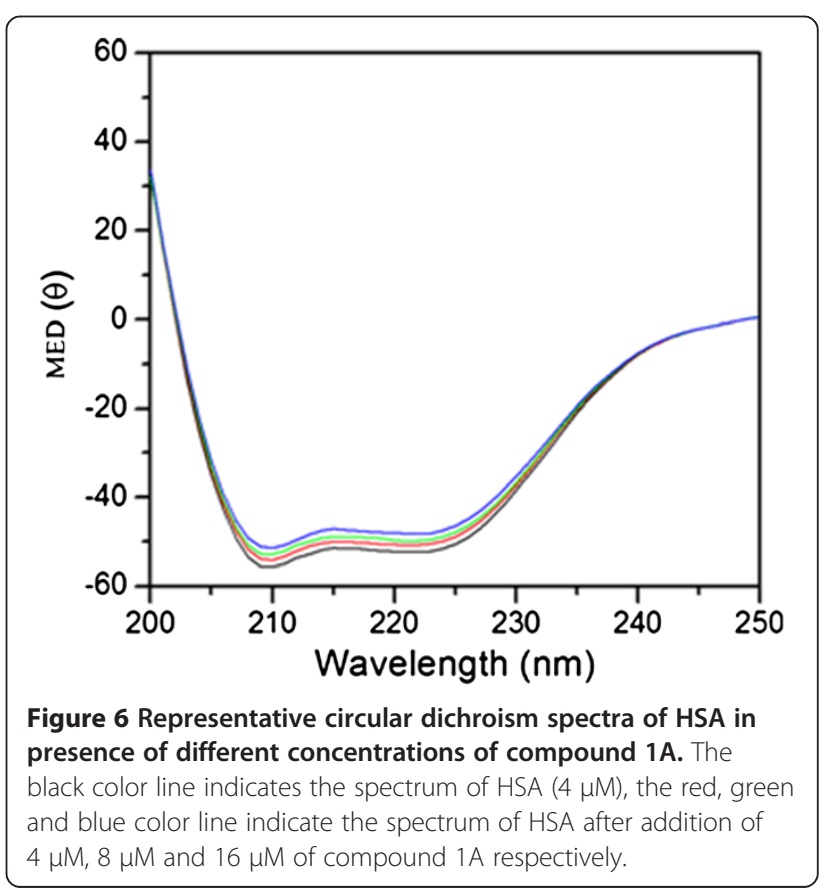


protein as evident from the change in the $\mathrm{CD}$ spectra (Figure 6).

Computational chemistry and molecular modeling studies. BSA and HSA are the major carrier proteins of the serum. These proteins bind to a variety of small molecules, mostly non-specifically, and can strongly affect the way they are delivered through the body. Fluorescence perturbation experiments show that the compounds bind very well with serum albumins, which is also corroborated by docking experiments. Docking of a ligand into a protein binding site and estimating the binding affinity of the resulted complex allow understanding the interaction pattern of a small molecule at the binding site. This information provides vital clues to design structure-based drug molecules. Docking analysis in the current investigation carried out to theoretically evaluate the ability of the compounds to bind serum albumins and the binding site of the receptor. Negative binding energy for the docked conformations (Figure $7 \mathrm{~A}$ and $7 \mathrm{C}$ ) indicates that the binding was thermodynamically favourable. Binding
Table 3 Thermodynamic parameter of binding as obtained from molecular docking simulation experiments

\begin{tabular}{ccc}
\hline Compounds & \multicolumn{2}{c}{ Binding free energy $\left(\mathrm{kcal}^{\mathbf{~ m o l}}{ }^{-1}\right)$} \\
\cline { 2 - 3 } & HSA & BSA \\
\hline 1A & -4.84 & -4.22 \\
\hline 1B & -4.55 & -3.80 \\
\hline 1C & -5.02 & -4.67 \\
\hline 1D & -4.90 & -5.18 \\
\hline
\end{tabular}

free energies for the best docked conformations are listed in Table 3. Here, each docking experiment was a composite of 100 independent iterations producing hundred best docked conformations all of which were arranged according to their binding energy in Figure $7 \mathrm{~A}$ and $7 \mathrm{C}$. In all the cases, the low energy binding modes indicate thermodynamically favourable interaction. Binding of $1 \mathrm{C}$ and $1 \mathrm{D}$ with the serum albumins appears to be slightly better than that of $1 \mathrm{~A}$ and 1B. However, no such narrow discrimination
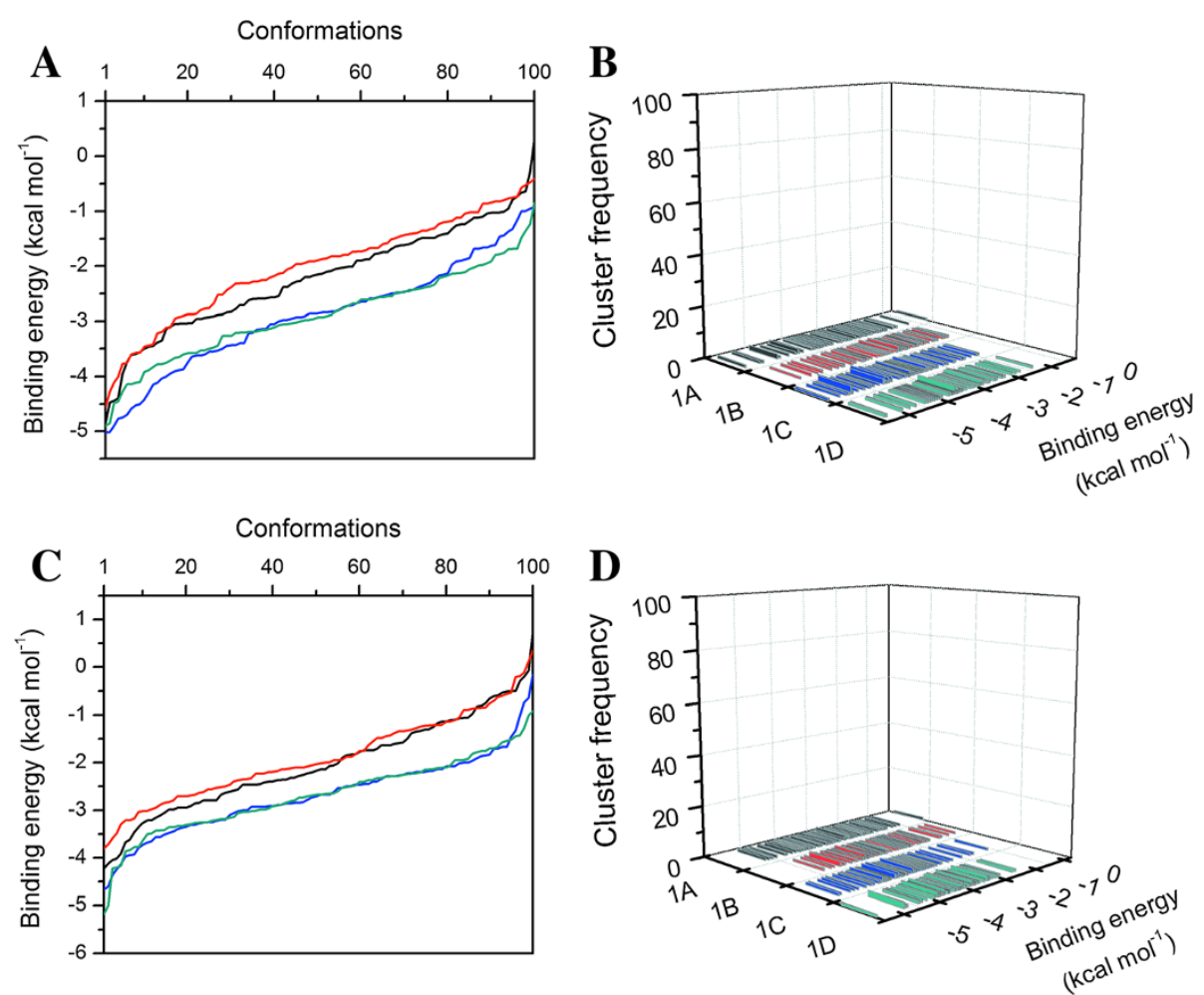

Figure 7 Energy spectrum distribution of the bound conformations for HSA (A) and BSA (C). All the best output from 100 independent docking simulations were arranged according to their binding energy. Very low energy conformations indicate thermodynamically favorable interaction. Binding of $1 \mathbf{C}$ and $1 \mathbf{D}$ with both the HSA and BSA were found to be better than that of $1 \mathbf{A}$ and $1 \mathbf{B}$. But the inconsistency in the low energy binding modes suggests nonspecificity. Clustering of the bound conformations for HSA (B) and BSA (D). Binding modes within $2 \AA$ standard deviation and $0.5 \mathrm{kcal} \mathrm{mol}^{-1}$ energy tolerance levels were clustered together. Although the low energy binding modes are prevalent no significant clustering was observed again suggesting no specificity in binding. 


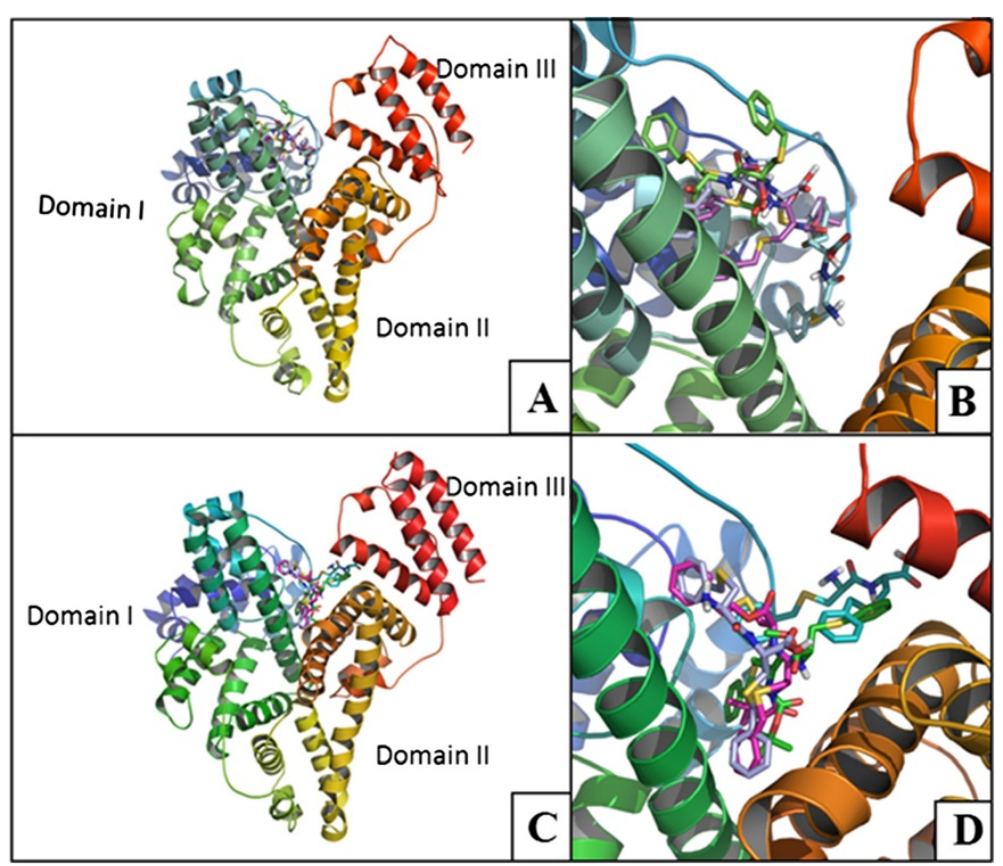

Figure 8 Ribbon representation of HSA (A) and BSA (C) docked with best binding modes of all ligands along with the close up views, (B) and (D) respectively. Ribbons are colored in rainbow; blue to red encompassing N-terminal to C-terminal of the proteins. 1A 1 , B, 1C and 1D are shown in stick models colored in green, magenta, light blue and cyan respectively. In case of HSA best binding modes are found to be in the domain I and for BSA best binding modes clustered in between the domain I and III.

could be established from our experimental results. Specificity of binding can be shown in terms of reproducibility of the docked conformation of the compounds. The docked conformations within $2 \AA$ standard deviation and $0.5 \mathrm{kcal} \mathrm{mol}^{-1}$ energy tolerance levels were grouped together into a cluster. Despite of the thermodynamically favorable interaction docking outcomes for each experiment showed no cluster formation (Figure 7B and 7D). Thus, the lack of reproducibility of the docked conformations within 2 $\AA$ standard deviation in space, suggests that the binding was nonspecific in nature. The best docked conformations are shown in Figure 8. For HSA the best docked conformation show that these compounds bind in the domain I and in case of BSA they bind between domain I and III. Serum albumins have many fatty acid binding sites. Seven such sites are reported for HSA, of which one site lies in domain I [34].

Domain I also binds to other drug molecules such as, 2,3,5-triiodobenzoic acid [35]. Small molecules are also reported to bind in to a site in between the domain I and III of HSA [34]. The major contributing forces involved in the binding of these compounds with serum albumins are hydrogen bonding (Additional file 1: Figure S4 and Additional file 1: Figure S5), hydrophobic interaction and van der Waals attraction.

\section{Conclusion}

In conclusion, in this work, we have synthesized four dipeptides made of cystine amino acid (both protected and unprotected form) and studied their interaction with BSA and HSA. Routine solution phase synthesis was employed to prepare these peptides. The cell viability of these compounds was quantified by MTT assay. They show anticancer activity in sub micro molar range. The phase contrast images show massive cell death. The interaction between these compounds with HSA and BSA was investigated by employing different spectroscopic techniques (fluorescence and CD spectroscopy). Fluorescence study indicates strong binding of these compounds with both BSA and HSA. The CD results revel that the secondary structure of BSA and HSA were very slight affected upon interaction with these compounds. The molecular modeling studies show that the binding of these compounds with BSA and HSA are thermodynamically favorable and no cluster formation occurs, which suggest that the bindings are nonspecific in nature. Although detail mechanistic studies of anticancer properties of these molecules are still going on, the initial results indicate DNA intercalation (Additional file 1: Figure S6) may be responsible for the cell death. Further studies in this aspect are going on in our laboratory and the results will be published in due course of time. 


\section{Additional file}

Additional file 1: contains the detailed synthetic procedure and characterization data of these molecules, computational method for partition coefficient (cLogP), detailed mathematical background of fluorescence study, Figures S1-S6, and Table S1.

\section{Competing interests}

The authors declare that they have no competing interests.

\section{Authors' contributions}

BB, SKP and UP and NCM conceived and designed the experiments. SKP and UP performed the experiments. All the authors analyzed the data. SKP and UP drafted the manuscript. All authors read and approved the final manuscript.

\section{Authors' information}

Biswadip Banerji achieved the following in his academic years: M.Sc. in Chemistry, University of Calcutta, Kolkata, India; Ph.D., Indian Institute of Technology, Kanpur, India; Postdoctoral Research Fellow from Oxford Centre for Molecular Science \& Chemistry Research Laboratory, Oxford University, UK; and Postdoctoral Research Fellow from the School of Chemical and Life Sciences, Institute of Chemical \& Engineering Sciences-Agency for Science, Technology and Research (ICES-A*STAR), Singapore. He was the Team Leader at Chembiotek, Kolkata, India. He is a Senior Scientist from the Indian Institute of Chemical Biology, Kolkata, India. His research area interests cover smart nanobiomaterials, peptide based drug designing, self assembly of biomaterials and natural product derived hybrid scaffolds and its application in therapeutics.

Sumit Kumar Pramanik obtained his B.Sc. in chemistry from Vidyasagar University, India. He earned his M.Sc. in applied chemistry from Bengal Engineering and Science University, Shibpur, India. He is a Ph.D. Student from the Chemistry Division, Indian Institute of Chemical Biology, Kolkata, India. His research area interests include nanobiomaterials and peptide based drug design and biophysical chemistry.

Uttam Pal earned his B.Sc. in Physiology from the Presidency College, Kolkata, India. He is a M.Sc. degree holder of Biophysics and Molecular Biology from University of Calcutta, Kolkata, India. He is a Ph.D. Student from the Structural Biology and Bioinformatics Division, Indian Institute of Chemical Biology, Kolkata, India. His research area covers structural biology and bioinformatics.

Nakul Chandra Maiti achieved M.Sc. in Chemistry, University of Calcutta, Kolkata, India; Ph.D. From Tata Institute of Fundamental Research, Mumbai, India; Postdoctoral JSPS visiting scientist, Institute for Molecular Science, Japan; Postdoctoral Senior Research Associate, Biochemistry, Case, Cleveland, Ohio, USA; Postdoctoral Research Associate/lecturer, California State University, Los Angeles, USA. He is a Senior Scientist from the Indian Institute of Chemical Biology, Kolkata, India. His research area interests cover structure based amyloid research, structural aspects and in-vitro behavior of natively unfolded proteins and peptides those are linked to human diseases, applications of NMR, fluorescence and Raman spectroscopy to biological systems, computational biochemistry and bioinformatics.

\section{Acknowledgements}

Sumit Kumar Pramanik thanks CSIR, India, Uttam Pal thanks INSPIRE Fellowship Programme, DST, India for financial support. We would also like to thank the miND project, CSIR for providing financial assistance towards this work. The authors would also like to thank the central instrumental fascilities of CSIR - IICB.

\section{Author details}

'Department of Chemistry, CSIR-Indian Institute of Chemical Biology, 4, Raja S.C. Mullick Road, Kolkata 700032, India. ${ }^{2}$ Department of Structural Biology and Bioinformatics, CSIR-Indian Institute of Chemical Biology, 4, Raja S.C. Mullick Road, Kolkata 700032, India.

Received: 19 January 2013 Accepted: 15 May 2013

Published: 24 May 2013
References

1. Boyle P, Leon ME: Epidemiology of colorectal cancer. Br Med Bull 2002, 64(1):1-25.

2. Tishler M: Impact of research on the growth of medicinal chemistry. J Chem Educ 1960, 37(4):195.

3. Weston AD, Hood L: Systems Biology, Proteomics, and the Future of Health Care: Toward Predictive, Preventative, and Personalized Medicine. J Proteome Res 2004, 3(2):179-196.

4. Peterlik M: Vitamin D insufficiency and chronic diseases: Hype and reality. Food Function 2012, 3(8):784-794.

5. Boring CC, Squires TS, Health CW: Cancer statistics for african americans. CA A Cancer J Clinic 1992, 42(1):7-17.

6. Sheehan JM, Young AR: The sunburn cell revisited: an update on mechanistic aspects. Photochem Photobio/ Sci 2002, 1(6):365-377.

7. Bell IM, Stirdivant SM, Ahern J, Culberson JC, Darke PL, Dinsmore CJ, Drakas RA, Gallicchio SN, Graham SL, Heimbrook DC, Hall DL, Hua J, Kett NR, Kim AS, Kornienko M, Kuo LC, Munshi SK, Quigley AG, Reid JC, Trotter BW, Waxman LH, Williams TM, Zartman CB: Biochemical and Structural Characterization of a Novel Class of Inhibitors of the Type 1 Insulin-like Growth Factor and Insulin Receptor Kinases. Biochemistry 2005, 44(27):9430-9440.

8. Lachance H, Wetzel S, Kumar K, Waldmann H: Charting, Navigating, and Populating Natural Product Chemical Space for Drug Discovery. J Med Chem 2012, 55(13):5989-6001.

9. Walsh DP, Chang Y-T: Chemical Geneticst. Chem Rev 2006, 106(6):2476-2530.

10. van Dongen SFM, de Hoog H-PM, Peters RJRW, Nallani M, Nolte RJM, van Hest JCM: Biohybrid Polymer Capsules. Chem Rev 2009, 109(11):6212-6274.

11. Sakurai K, Uezu K, Numata M, Hasegawa T, Li C, Kaneko K, Shinkai S: [small beta]-1,3-Glucan polysaccharides as novel one-dimensional hosts for DNA/RNA, conjugated polymers and nanoparticles. Chem Commun 2005, 35:4383-4398

12. Svenson J, Stensen W, Brandsdal B-O, Haug BE, Monrad J, Svendsen JS: Antimicrobial Peptides with Stability toward Tryptic Degradationt. Biochemistry 2008, 47(12):3777-3788.

13. Huang YB, Wang XF, Wang HY, Liu Y, Chen Y: Studies on Mechanism of Action of Anticancer Peptides by Modulation of Hydrophobicity Within a Defined Structural Framework. Mol Cancer Ther 2011, 10(3):416-426.

14. Mendoza FJ, Espino PS, Cann KL, Bristow N, McCrea K, Los M: Anti-tumor chemotherapy utilizing peptide-based approaches-apoptotic pathways, kinases, and proteasome as targets. Arch Immunol Ther Exp (Warsz) 2005, 53(1):47-60

15. Riedl S, Zweytick D, Lohner K: Membrane-active host defense peptides - Challenges and perspectives for the development of novel anticancer drugs. Chem Phys Lipids 2011, 164(8):766-781.

16. Rohacova J, Sastre G, Marin ML, Miranda MA: Dansyl Labeling To Modulate the Relative Affinity of Bile Acids for the Binding Sites of Human Serum Albumin. J Phys Chem B 2011, 115(35):10518-10524.

17. Svenson J, Brandsdal B-O, Stensen W, Svendsen JS: Albumin Binding of Short Cationic Antimicrobial Micropeptides and Its Influence on the in Vitro Bactericidal Effect. J Med Chem 2007, 50(14):3334-3339.

18. Rahimipour S, Ben-Aroya N, Ziv K, Chen A, Fridkin M, Koch Y: ReceptorMediated Targeting of a Photosensitizer by Its Conjugation to Gonadotropin-Releasing Hormone Analogues. J Med Chem 2003, 46(19):3965-3974.

19. Clancy HA, Sun H, Passantino L, Kluz T, Munoz A, Zavadil J, Costa M: Gene expression changes in human lung cells exposed to arsenic, chromium, nickel or vanadium indicate the first steps in cancer. Metallomics 2012, 4(8):784-793.

20. McLaughlin CA, Pitot HC: The effect of various treatments in vitro and in vivo on the binding of 125I-labeled antirat serum albumin Fab' to rat tissue polyribosomes. Biochemistry 1976, 15(16):3541-3550

21. Gombotz WR, Pettit DK: Biodegradable Polymers for Protein and Peptide Drug Delivery. Bioconjug Chem 1995, 6(4):332-351.

22. Liu W, Li X, Wong Y-S, Zheng W, Zhang Y, Cao W, Chen T: Selenium Nanoparticles as a Carrier of 5-Fluorouracil to Achieve Anticancer Synergism. ACS Nano 2012, 6(8):6578-6591.

23. Banerji B, Pramanik SK, Pal U, Maiti NC: Conformation and cytotoxicity of a tetrapeptide constellated with alternative D- and L-proline. RSC Advances 2012, 2(17):6744-6747

24. Lakowicz JR: Principles of Fluorescence Spectroscopy. 3rd edition. Springer Science+Business Media, LLC 2006:288-289. 
25. Bian Q, Liu J, Tian J, Hu Z: Binding of genistein to human serum albumin demonstrated using tryptophan fluorescence quenching. Int J Biol Macromol 2004, 34(5):275-279.

26. Eftink MR, Ghiron CA: Fluorescence quenching of indole and model micelle systems. J Phys Chem 1976, 80(5):486-493.

27. Morris GM, Huey R, Lindstrom W, Sanner MF, Belew RK, Goodsell DS, Olson AJ: Autodock4 and AutoDockTools4: automated docking with selective receptor flexiblity. J Comput Chem 2009, 16:2785-91.

28. Sanner MF: Python: A Programming Language for Software Integration and Development. J Mol Graphics Mod 1999, 17:57-61.

29. Banerjee M, Pal U, Subudhhi A, Chakrabarti A, Basu S: Interaction of Merocyanine 540 with serum albumins: photophysical and binding studies. J Photochem Photobiol B 2012, 108:23-33.

30. Ray A, Seth BK, Pal U, Basu S: Nickel(II)-Schiff base complex recognizing domain II of bovine and human serum albumin: Spectroscopic and docking studies. Spectrochim Acta A Mol Biomol Spectrosc 2012, 92:164-174.

31. Alam A, Pal C, Goyal M, Kundu MK, Kumar R, labal MS, Dey S, Bindu S, Sarkar S, Pal U, Maiti NC, Adhikari S, Bandyopadhyay U: Synthesis and bio-evaluation of human macrophage migration inhibitory factor inhibitor to develop anti-inflammatory agent. Bioorg Med Chem 2011, 19(24):7365-73.

32. Rudra DS, Pal U, Maiti NC, Reiter RJ, Swarnakar S: Melatonin inhibits matrix metalloproteinase- 9 activity by binding to its active site. J Pineal Res 2013, 54(4):398-405. doi:10.1111/jpi.12034.

33. Bhowmik A, Das N, Pal U, Mandal M, Bhattacharya S, Sarkar M, Jaisankar P, Maiti NC, Ghosh MK: 2,2'-Diphenyl-3,3'-Diindolylmethane: A Potent Compound Induces Apoptosis in Breast Cancer Cells by Inhibiting EGFR Pathway. PloS One 2013, 8(3):e59798.

34. Bhattacharya AA, Grüne T, Curry S: Crystallographic analysis reveals common modes of binding of medium and long-chain fatty acids to human serum albumin. J Mol Biol 2000, 303(5):721-732.

35. Curry S, Mandelkow H, Brick P, Franks N: Crystal structure of human serum albumin complexed with fatty acid reveals an asymmetric distribution of binding sites. Nat Struct Biol 1998, 5(9):827-35.

doi:10.1186/1752-153X-7-91

Cite this article as: Banerji et al:: Potent anticancer activity of cystinebased dipeptides and their interaction with serum albumins. Chemistry Central Journal 2013 7:91.

\section{Publish with ChemistryCentral and every scientist can read your work free of charge \\ "Open access provides opportunities to our colleagues in other parts of the globe, by allowing anyone to view the content free of charge." \\ W. Jeffery Hurst, The Hershey Company. \\ - available free of charge to the entire scientific community \\ - peer reviewed and published immediately upon acceptance \\ - cited in PubMed and archived on PubMed Central \\ - yours - you keep the copyright \\ Submit your manuscript here: \\ http://www.chemistrycentral.com/manuscript/<smiles>c1ccccc1</smiles> \\ Chemistry Central}

